\title{
INTERNET MEMES AS FORM OF CULTURAL DISCOURSE: A RHETORICAL ANALYSIS ON FACEBOOK
}

\author{
Najma Akhther, M.A., M.S.S. \\ Ph.D. Student (current) \\ Department of Communication \\ Wayne State University \\ Assistant Professor (on study leave) \\ Department of Journalism \& Media Studies \\ Jahangirnagar University, Bangladesh
}

This is a preprint version of the manuscript, which has not been peer-reviewed.

Author Disclosure: This study was presented at the international conference on visual South Asia: Anthropological Exploration of Media and Culture, University of Dhaka, Dhaka, Bangladesh.

Recommended Citation: Akhther, N. (2017, May 10-11). Internet meme as a form of cultural discourse: A rhetorical analysis on Facebook [Conference presentation]. International conference on visual South Asia: Anthropological Exploration of Media and Culture, Dhaka, Bangladesh. 


\begin{abstract}
Internet memes are phenomena that rapidly gain popularity on the Internet which construct intercultural discourse. Using visual rhetoric, the Internet memes convey a set of symbols and ideals that express socio-political structure represented on the Internet. The story of memes is crucial in understanding the digital culture along with revealing the identity of an Internet subculture, as well as in analyzing the impacts of this cultural artifact. This study analyzes the nature and functions of internet memes and its contribution to formulate a new cultural discourse. The findings have been instrumented to illustrate how memes operate as rhetoric to explore the intercultural communication and identity construction prevalent in representative cyber-culture. It has specially been targeted to inquire the inter-textual nature of memes which are created and disseminated by the Bangladeshi Facebook prosumers. In addition, the study makes a comparison of theoretical approaches to the study of memes, including visual rhetoric approach which combines elements of the semiotic and discursive approaches to study the persuasive constituents of visual texts. These methods help deconstruct a sign or a text and decode possible hidden meanings through discourse analysis in terms of written texts and through semiotic analysis in terms of images. The presence of both an image (sign) and a caption (text) in an internet meme requires such a combined approach for reflective output.
\end{abstract}

Keywords: social media, cyber-culture, prosumers, cultural discourse, Internet memes, Facebook, visual rhetoric, discourse analysis, semiotic analysis 


\section{Internet Memes as Form of Cultural Discourse: A Rhetorical Analysis on Facebook Introduction}

In contemporary society, media communication is mostly held through various social media platforms (Ohiagu \& Okorie: 2014, p. 93). Social media as 'a group of Internet-based applications that has been built on the ideological and technological foundations of web 2.0, and that allows the creation and exchange of user-generated contents' (Kaplan \& Haenlein 2010). The new electronic independence re-creates the world in the image of a global village (McLuhan 1964). New Media has united the entire world under the umbrella of technology. In this pervasive new media context, we live in the era of participatory cyber-culture, the power of making culture lies in the hands of consumers, indicated to the ubiquity of the 'prosumer' (Toffler 1980). Prosumer defined as someone who blurs the distinction between a 'consumer' and a 'producer' (William Gerhardt:2008,1). At present, the relation between producer and consumer has built up a distinct prosumer culture. One of the main cultural contents of cyberculture and cyber-communication turns significant in this context that is internet memes. Despite being sidelined from the mainstream cultural discourses for a long time, in today's social interaction and communication, significance of internet memes is limitless and expanding. The term Internet meme refers to an idea, behavior or style that spreads from person to person within a culture (Dawkins 1989). The meme may take the form of an image, hyperlink, video, website or hashtag. It alludes to a theory of biologist Richard Dawkins (1976) who postulates memes as melodies or fashion trends replicated among online based communities. Exceeding the mere tradition of sharing funny picture or emotions, meme upholds the richness and uniqueness of its language. Lately, the growing public interest in internet memes results in the amalgamation and distribution of significant number of contents among prosumers on popular websites such as 
Facebook, Twitter, or YouTube. It is Facebook, above all, which deserves a particular attention here.

Facebook is the most popular social networking sites throughout the world which is the first social network to surpass 1 billion registered accounts and currently sits at 1.59 billion monthly active users as of April 2016 ranked by a number of active accounts (Statista 2016). Every 60 seconds on Facebook: 510 comments are posted, 293,000 statuses are updated, and 136,000 photos are uploaded (Facebook, Investor Relation 2016). As the world's largest social network site, Facebook has become an inevitable part of our daily life, influencing society, economics, culture, and politics. In case of internet memes, users or institutions usually post memes on their profiles, viewable anytime by the rest of netizens. The prosumers may approve such memes pressing 'I like it' option as well as commenting below or sharing. Increase of 'likes' makes the promotion of a page easier (which is most important in the case of commercial companies). This speed up the dispersion of the memes easily along with the acknowledgement of positive attitude toward it. The aim of this study is to analyze the growing popularity of internet memes and its contribution to formulate a new cultural discourse. The study is tried to scrutinize the inter-textual nature of internet memes to evaluate their functions, Internet memes contribution to frame and create intercultural rhetorical discourse and the active role in constructing a pragmatic participatory rhetoric especially stimulated by the Bangladeshi Facebook prosumers.

\section{Internet memes and participatory digital culture}

Internet memes are an emerging form of discourse currently prevalent in online discussion forums, social media and general Internet culture. The term Internet meme has become an integral part of the netizen vernacular and it also turned the spread of memes into a highly visible 
practice. Jenkins (2009a) described Internet memes exist as artifacts of participatory digital culture. 'Participatory culture' has been of increasing interest to media scholars and practitioners over the last decade. Jenkins explained the participatory culture is a culture with relatively low barriers to artistic expression and civic engagement, strong support for creating and sharing one's creations, and some type of informal mentorship whereby what is known by the most experienced is passed along to novices (Jenkins 2009a).

Biologist Richard Dawkins(1976) first posited the term 'meme' in the English lexicon from his book, 'The Selfish Gene', as an attempt to explain the way cultural information spreads; within Internet culture the term is commonly used to refer to phrases, videos, images, or a combination thereof that are widely propagated by Internet users. This usage of the term has further evolved to refer to a specific type of Internet artifact consisting of a combination of images and text generally understood as intending to be found humorous by viewers. This specific form of Internet artifact is known as an 'image macro', defined by the Oxford online dictionary as 'a photographic image on which a humorous caption or catchphrase has been digitally superimposed'. Typically there are two lines of text, one at the top of the image serving as the set-up for a joke, and another at the bottom of the image serving as the punch line. Wiggins \& Bowers (2014) also describe memes as remixed, iterated messages; rapidly spread by members of participatory, digital culture for the purposes of continuing a conversation.

Any Internet user can create a new meme on meme generating sites, such as memegenerator.net, knowyourmeme.com, quickmeme.com and memecnter.com. Among these meme-creator sites the 'Meme Generator', ranks memes by popularity and the meme reference site of record, Know Your Meme (knowyourmeme.com), has popular and trending lists. These sites contain the instructions or blueprints (templates) needed to create memes. In this way, the 
Internet assists both the spread of Internet memes and traditional memes (in an online environment) because it accelerates not only of texts that were previously identified with oral traditions, such as urban legends and jokes, but also as nesting the creation of spreadable new visual genres of expression (Shifman 2012: 189). Moreover, memes can be accessed any time and place (Blackmore 1999, 216). In other words, memes can appear anywhere regardless of geographical and cultural boundaries (Marshall 1995: 3) and they can be copied with a 100\% accuracy rate. It also provides a powerful new way to combine few things such as- creativity, art, message, and humor in the internet culture. Public relations, advertising, and marketing professionals have effectively used Internet memes as a form of viral marketing to create marketing 'hype' for their product or service. Internet memes are considered as cost effective and sometimes become a trend. The practice of using memes to market products or services is known as memetic marketing (Floor 2000).

In addition, memes often re-appropriate dominant discourses such as- summer blockbusters like Inception, public figures like Donald Trump, Barack Obama, Pop culture staples like the hipster, and political movements like Occupy Wall Street. But re-appropriation, by definition, does not mean complete independence from these discourses. Besides, memes are used to represent discourses and identities which anytime this occurs there's political work occurring too. Aside from sustaining popularity among Internet users, memes have also received attention from journalists, academics, and media organizations that have borrowed elements of Internet memes for advertising and marketing efforts. Examples include television commercials for Vitamin Water brand beverages and print ads for Cadbury candies (Myhre 2012).

Hence internet memes constitute a peculiar expression of the involvement of their authors in the public issues. Not unlike rumours, jokes or urban legends, internet memes often comment on the 
current reality. Information related to public issues appearing in the mass media becomes another source of material to the authors of memes.

Today, there are numerous social networking sites and all are playing the extended role of society, however, for this research, Facebook is the primary focus. Facebook has gained popularity as a participatory discussion forum for the postmodern prosumers. Bangladesh, one of the next eleven countries in the world with more than 160 million people, is experiencing an exponential growth of Facebook users. Facebook has appeared to be the third most popular website and most popular social networking sites in the country (Alexa.com 2016). The number of Facebook users in Bangladesh was only 10,000 in 2008; now the figure stood at 2.1 million as of June 2016 (Internet World Stats 2016). A new user of social networking site Facebook is being added in every 12 seconds in Bangladesh which is more than the birth rate of the country (Sujan 2015). So, Bangladeshi Facebook prosumers, in particular, the young generation is enchanted with this site as it facilitates them with the chances like uploading photo and profile among the people of the virtual community, expressing one's opinions, chatting, creating fan clubs dedicating to the person or object of interest. Among the objects uploaded on Facebook, meme creating and sharing tendency is getting popularity in the context of public issues. Prosumers deriving from any category of the society are exposing their opinion and expression virtually more vibrantly than in the real world as it ensures a distinct sort of participatory cultural representation.

\section{The Rationale of the Research}

The advance of digital technology and the Internet has unexpectedly nurtured a new form of cultural media that is Internet memes. Although Internet meme remains relatively understudied yet, more scholars have already brought into context the implications of Internet 
memes for building identity, forming public discourse, and encouraging civic participatory engagement (Huntington 2013; Knobel \& Lankshear 2007; Milner 2012; Mina 2012; Peck 2014). Moreover, Internet memes involve interactions between visual consumption and discursive processing (Huntington 2013). Social networking sites especially, Facebook has been playing revolutionary roles as participatory media. Facebook prosumers are making Internet memes meaningful collectively because of their shared meaning in a communal setting. Besides, prosumers are interacting with social, cultural and political issues to create and share internet memes. Bangladesh has not lagged behind this cultural phenomenon. Facebook pages and individuals' profiles have assumed very influential roles in many aspects like public issues. Bangladeshi Facebook prosumers have experienced both socially optimistic roles as well as creations of propaganda throughout the virtual space. Hence, in their contemporary perspective, it is an imperative matter to analyze the inter-textual nature of memes as a unique form of visual rhetoric which play active role in constructing form of participatory rhetoric especially among the Bangladeshi Facebook prosumers.

\section{The Objective of Research}

The main objective of the present research is to examine how memes operate as rhetoric to explore the intercultural communication and identity construction being represented in such participatory media culture. It is specially targeted to identify the inter-textual nature of memes as a unique form of cultural discourse which has been shared by the Bangladeshi Facebook prosumers. This study has some particular motives:

» To explore the Internet meme sharing trend among Bangladeshi prosumers;

» To scrutinized the nature and functions of internet memes

» To know the propensity of sharing memes for the prosumers 
» To investigate how Internet memes framed and created intercultural rhetorical discourse After all, to examine the inter-textual nature of memes as form of participatory rhetoric among the Bangladeshi Facebook prosumers.

\section{Relevant Literature Review}

The Internet meme remains relatively new phenomena and understudied. However, more scholars have already begun to notice and analyze implications of Internet memes for instigating social awareness and action. Internet memes can be used for distinct purposes, such as entertainment, aesthetics, satire, and resistance. They are a form of public persuasion and serve different purposes with different strategies (Huntington 2013). The creation, circulation, recreation and re-dissemination of memes have been hugely influenced by the network of Internet users (Jenkins 2014). The meme consumers are also influenced by the development of Internet memes, which revealed a new approach to interactions and public participation among people (Shifman 2014).

Turhan (2013) analyzed Internet memes especially focusing on how the relation between images, text, and meanings using semiotics and connecting with each other to form social messages, political, universal emotions or even just to be funny and entertain its users. Internet memes serves as a humorous way to have fun with context, words, images, meaning, symbols, culture, popular culture and etc. Baym's (2012) also depicted that the internet memes as a means to transform established cultural texts into new ones, to negotiate the worth of diverse identities, and to engage in unconventional arguments about public policy and current events. Memes were a mix of old inequalities and new participation. Participation makes Internet memes meaningful collectively (Brown 2014). In that case, Internet memes are recognizable because of their shared 
meaning in a communal setting. Besides, the power of community potentially can be increased along with participation in the process (Hristova 2013).

Spitzberg (2014) utilized the spiral of silence effect to illustrate that the cooperative memes assistant minority groups give voice to their memes in the mainstream discourse. Nevertheless, stereotypical assumptions and hegemonic culture also make Internet memes (Vickery, 2014). For example, in the 'High Expectation Asian Father' meme series, racial minority and mainstream stereotypes toward Asians have been depicted (Nakamura, 2002). Similarly, Ryan Milner (2013) introduced the 'logic of lulz', 'Lulz' derived from 'lol' or 'laughing out loud'. This study showed that race and gender representations in those Internet image-based memes were dominated by stereotypes. However, the 'logic of lulz' relying on irony and critique facilitated dominant and counter discourse.

Ding (2015) examined the use of Internet memes as persuasive discourses for entertainment, spreading stereotypes, and online activism by analyzing the meme images and texts, including their content, rhetorical components, and structure. The findings indicated that Internet memes complicate the construction of racial identity, invoking the negotiation and conflicts concerning racial identities described by dominant as well as vernacular discourses. Huntington (2013) noted that internet memes are a form of representational discourse that subverts dominant media messages to create new meaning.

Carl Chen (2012) traced the phenomenon of internet meme back to its roots in the site 4chan and examined the forum using Habermas's idea of public spheres and Macdonald's theory of mass culture while also providing insight on the political culture promoted by these Internet communities. Firstly, users participated in this public sphere because of their common cultural interests and only began to take action to protect its values once they realized their culture could 
be threatened by government censorship, corporate control or by the forum's leadership (Chen 2012). On other hand, Sulhan (2016) was used the Barthes 'Semiology Theory' in order to analyze the denotative and connotative meanings of Internet memes; one of them was the 'Scumbag Steve'. This study appeared that the 'Scumbag Steve' and other Internet memes in general are not just forms of entertainment, but rather also used as a means of communication (Sulhan 2016).

Thus, it can be said that social media have provided the most fertile environment for the replication of memes to date. It is found that although a social networking user tries to portray him/herself in an idealised manner, these memetic connotations give a true impression of his/her offline persona. As a result, there is not much difference between the user's online and offline personae. So, memes also play a vital role in the construction of Facebook personae (Preez \& Lombard 2014).

This discussion makes it clear that internet memes convey such messages which are influencing the public mind and reflecting the inter-cultural phenomenon. But there is no discernible study regarding the Bangladesh perspectives. So, it is imperative to know the nature of internet meme culture among the Bangladeshi netizens.

\section{Theoretical Framework}

The contents of research have been analyzed based on the theory of Visual rhetoric. Visual rhetoric is the fairly recent development of a theoretical framework describing how visual images communicate, it is one's ability to understand what an image is attempting to communicate. Sonja Foss defines visual rhetoric as communicative artifact generated through the use of visual symbol for the purpose of communicating (Foss 2005). This can be a photograph, a stamp or even a video. In this study, selected Internet memes are rhetorical artifacts. The visual 
rhetoric approach combines elements of the semiotic and discursive approaches to analyze the persuasive elements of visual texts. Visual rhetoric understands visual texts as created to construct meaning (Foss: 2004, 304). Rhetoric is also considered to be persuasive. Blair (2004) claimed that visual arguments have the capability to draw viewers to the discursive construction. By considering memes as discourse and analyzing the semiotic elements in memes, researchers can examine how memes operate as rhetoric. A comparison of the semiotic, discursive and rhetorical approaches can analyze the visual rhetoric drawn from both the semiotic and discursive approaches for a comprehensive critique of the text. Foss (2004) developed a framework for visual rhetoric study — nature, function and evaluation (Foss: 2004, 307). Nature is primarily concerned with explication of the presented and suggested elements of the text. Applying insights of visual rhetoric to analyze Internet memes help reveal the image meaning encoded in such new visual forms associated with the Internet. Huntington (2013) considered that memes rely heavily on inter-textuality, because its nature is 'parodying, mimicking, and recycling' elements of visual media culture. Spread of internet memes depends on the combination of such various referents, and textual and pictorial juxtapositions (Knobel \& Lankshear 2007).

As a digital form of intercultural rhetoric, Internet memes are created based on how people perceive and presume their own culture. Through the modification of cultural elements, new meanings appear (Milner 2012). Milner (2012) deemed that such transformation of memes is based on the understanding of perceived representational images associated with certain individuals or groups. Thus, this study has tried to examine the Internet memes as rhetoric, to explore the social power relations and to understand how memes create intercultural 
communication and identity construction being represented in such participatory media culture without the boundaries of nationality or limitations of time and distance.

\section{Method}

The contents of the study have been examined by using the semiotic and discourse methods. These methods have been chosen as both of them are involved in deconstructing a sign or a text and making possible hidden meanings visible. Semiotics involves the analysis of cultural artifacts to discern how and what meanings are encoded and communicated through the interplay of signs such as words and images. On the other hand, the cultural lineage in discourse analysis draws heavily on Michel Foucault (1926-1984) who offers insight into the link between texts and discourses. Social semiotics is related to discourse analysis in that it concerns how people make meaning from cultural artifacts, but social semiotics includes signs and images in addition to verbal and linguistic material.

Since the composition of an internet meme often involves both - an image (sign) and a caption (text) - a mixture of both methods seems to be the best approach. Miltner (2011) takes a micro-level discursive approach to the analysis of memes as a method of understanding themes at play in larger, cultural-level discourses. Other scholars of memes echo an understanding of memes as tools to understand a culture at large (Burgess 2008; Miltner 2011); the idea of memes as a form of discourse appears to permeate work that frames memes as a literacy practice (Knobel \& Lankshear: 2007; Knobel: 2006; Lewis: 2012). The current study evinces the view that cultural meanings are created and communicated through the interplay of signs, which is the perspective of social semiotics; the artifacts under analysis in the present study are comprised of textual and visual elements, and cultural discourse analysis that examines internet meme as cultural artifacts. 


\section{Sampling Procedure}

To bring out a representative result of the research, the Internet memes have been selected from the Bangladeshi networks of Facebook. In that case, the Facbook page of 'eArki'(www.earki.com) has been picked out by using purposive sampling method. The page posts contents regularly on satire, news, political, social issues, sports and so on. Originally, it targeted the Bangladeshi Community. In this study, the Facbook page of 'eArki' has only been chosen to know the nature of posted memes as rhetorical artifacts. On the other hand, sample was taken from the timeline of the page from $1^{\text {st }}$ March 2017 to 31 March 2017.

The justification behind selecting 'eArki' as the sample because it is the most popular entertaining gag site in Bangladesh and 86.1\% Bangladeshi's Visit the site (Alexa.com 2017). According to socialbakers.com, $70.70 \%$ Facebook prosumers have popularized this page. Furthermore, the number of Facebook fans was remarkable as well which stood at 122, 568 in March 2017. So, selected samples have been presented for this study.

\section{Data Presentation and Analysis}

In this section, genres of collected Internet memes are presented and analyzed. Firstly, the memes have been analyzed from quantitative data to identify the nature of internet memes and then the memes scrutinized by discussing their structures and the constructing process for a better understanding of how Internet memes occur, transform, and the functions of internet memes according to the method of the research's objectives and theory of visual rhetoric.

\section{The nature of internet memes}

The memes posted by the page 'eArki' covered several types of information within it interests, therefore the contents reflect a distinctive categorization. The memes by 'eArki' could be categorized under general tags like national issues, political, social awareness, cultural, sports, 
entertainment and others (current events) issues. There are memes that reflect the everyday lives of Bengali people, social and cultural practices persisting in Bangladesh. All these broadly comprise the entertainment category. The findings of memes have been described below.

Table-1: Posted Memes and Interactive Nature among the Prosumers

\begin{tabular}{|c|c|c|c|}
\hline \multicolumn{4}{|c|}{ 1-31 March 2017 } \\
\hline Number of Memes & Likes & Comments & Shares \\
\hline 119 & 129,212 & 1023 & 5,519 \\
\hline
\end{tabular}

Abovementioned data depicted that memes are exemplars of participatory media because they are created and circulated by users. The findings also indicated that the Facebook page 'eArki' posts regular contents through internet memes. The prosumers approved such memes pressing 'I like it!' option as well as commenting below or sharing which also evinced that the meme page was much more interactive as participatory rhetorical artifacts.

Table-2: Comparison among the posted contents

\begin{tabular}{|c|c|c|}
\hline $\begin{array}{c}\text { Types of meme } \\
\text { content(Category) }\end{array}$ & Number of Content & \\
\hline 1. National & 15 & 12.60 \\
\hline 2. Political & 6 & 5.4 \\
\hline 3. Social & 5 & 4.20 \\
\hline 4. Cultural & 35 & 29.41 \\
\hline 5. Sports & 33 & 27.73 \\
\hline 6. Entertainment & 17 & 14.29 \\
\hline 7. Others(Current events) & 8 & 6.72 \\
\hline
\end{tabular}




\begin{tabular}{|c|c|c|}
\hline Total & 119 & - \\
\hline
\end{tabular}

The table drawn above makes it clear that Internet memes can be used for distinct purposes as form of public persuasion and serve different functions with different strategies. Aforementioned data showed that the meme page's shape intercultural communication on important national, political, social awareness, cultural, sports, entertainment and also on current events which ultimately represent the everyday's cultural practices of Bengali people. The findings also found that most of the content of memes posted on cultural issues which stood about $29.41 \%$. It is also mentionable that Bangladeshi Facebook prosumers like to represent their patriotism through sharing and discussing on sports issues especially cricket. The content of memes was not exception to this as it posted about $27.73 \%$ among the prosumers. For national issues, political, social awareness, entertainment and others current events the percentage stood consecutively $12.60 \%, 5.4 \%, 4.20 \%, 14.29 \%$ and $6.72 \%$. Hence it can be assumed that Internet memes in general are not just forms of entertainment, but rather also used as rhetoric to explore the intercultural communication.

\section{Internet memes as intercultural rhetorical discourse}

Based on the facts and findings on the representation of Internet memes, it can be picked out that Internet memes are created based on how people perceive and presume their own culture. Abovementioned findings also stated that internet memes are not unlike rumours, jokes or urban legends, internet memes often comment on the current reality. Internet users are invited to participate in such intercultural discussions to express their cultural perspectives, anxieties, anger, and fears. Therefore, such discourse constructs identities, integrating opinions, influencing attitudes, and shaping minds. This study found out some characteristics of internet memes which 
actually represent the intercultural communications of Bangladeshi prosumers. Rhetorical analysis of internet memes has been discussed below.

\section{Drawing public attention}

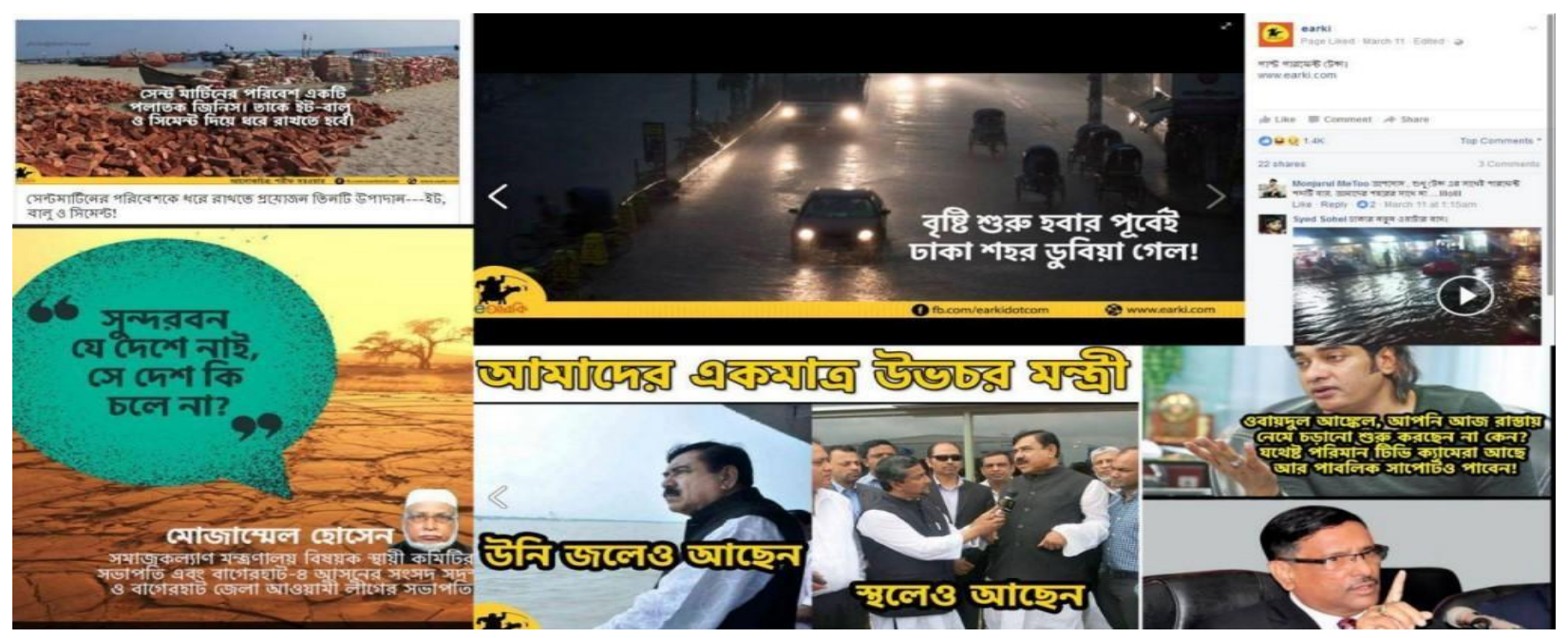

Figure-1: Internet memes

According to semiotic and discursive approaches, the memes (figure-1) represent the current crises of Bangladesh like communication scenario, environmental junctures of Saint Martin Island and present predicament of largest mangrove forest the Sundarban. Hence, it can be said that internet memes actually appeal the public mind and influence public agenda by sharing their opinion among the netizens vernacular.

\section{Indicating social awareness}




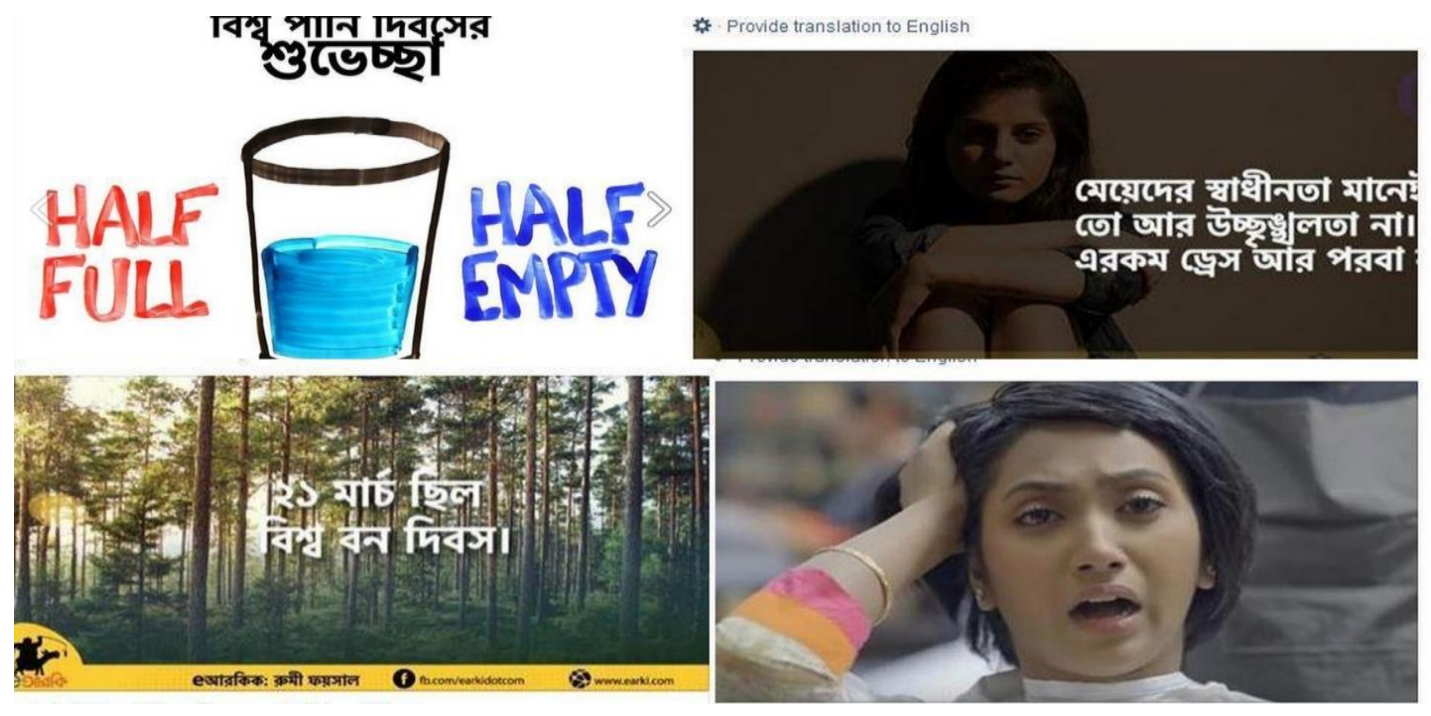

Figure-2: Internet memes

Abovementioned memes (figure-2) talk about the current reality. It is also indicated that Bengali prosumers should be conscious about issues like women's violence, deforestation, change their mental attitude toward women's freedom and equality. Thus, internet memes are attempted to create social awareness in the new public sphere which also impact on the proumers offline reality.

\section{Capturing digital culture}

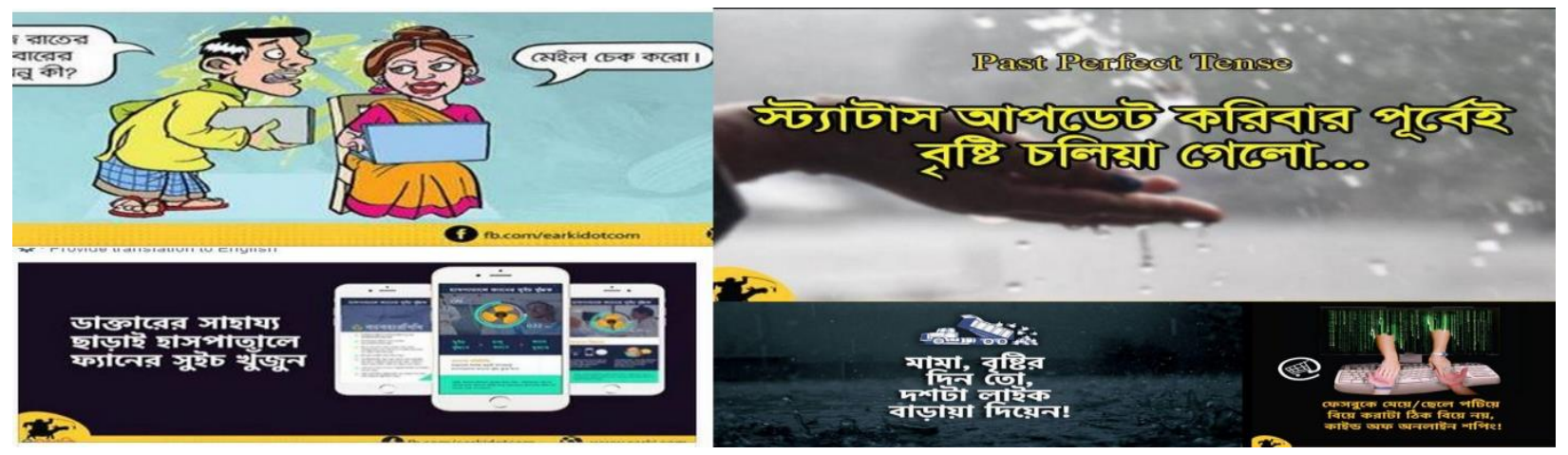

Figure-3: Internet memes

The meme figure-3 drawn makes it clear that social media are shaping the minds of prosumers, they always think about the virtual reality which influences their real life culture. Netizens are 
getting many basic services by dint of Internet technology such as health tips, online shopping and also can adopt various tips on everyday's life. Furthermore, internet artifacts are changing the patterns of relationship. In such case, internet memes are representing the virtual reality which ultimately reflecting the prosumer's real life.

\section{Influencing cultural attitudes}

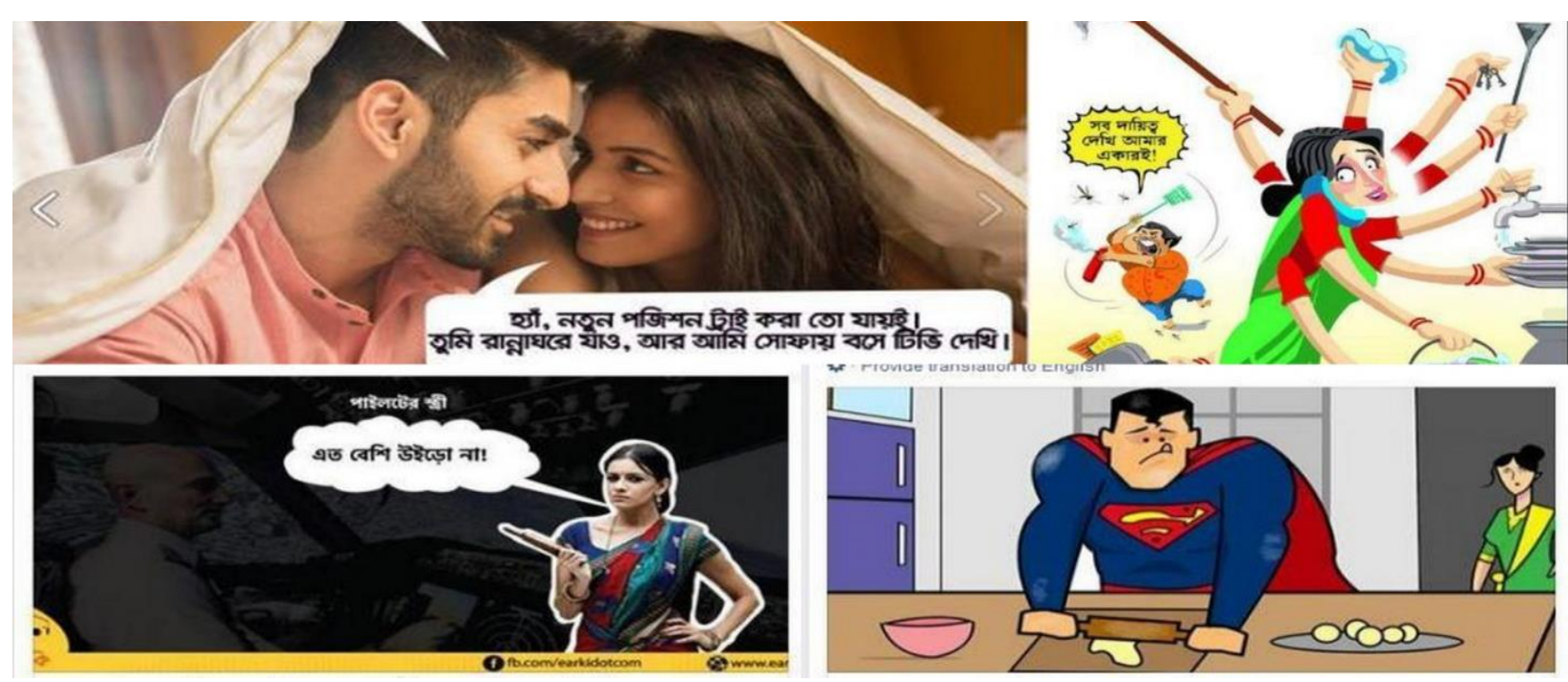

Figure-4: Internet memes

Aforesaid memes indicated the cultural attitudes which are being practiced around the world especially on gender roles. Cultural stereotype is a discursive affair all over the globe which talks about the roles of women within the society. Internet memes comprise these kinds of cultural practice which influence the netizens vernacular as well their cultural attitudes.

\section{Representing patriotism}




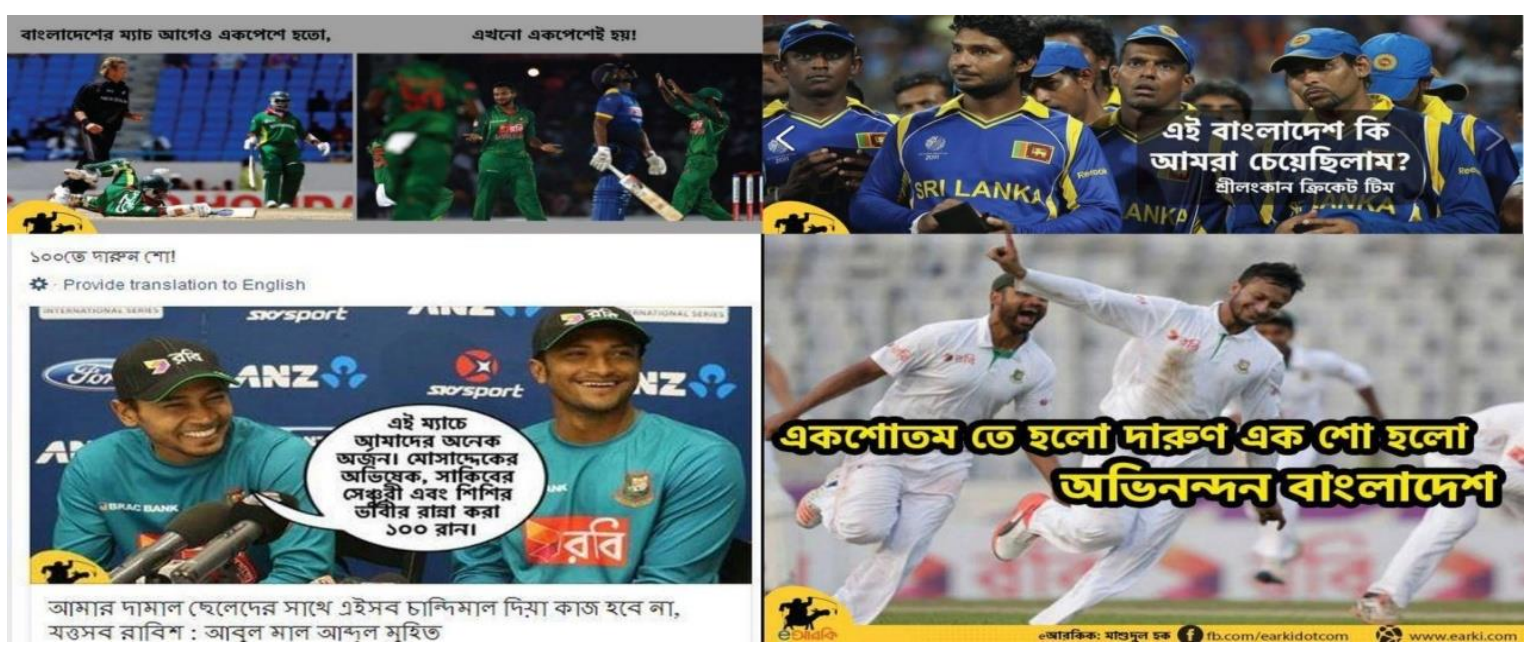

Figure-5: Internet memes

The meme figure-5 mainly focuses on Bangladesh cricket, it is alluring that Bangladeshi people love to talk about the cricket more than other sports because they think that Bangladesh is being represented all over the world due to the development in the cricket sector which also reflects their nationalism or patriotism. Facebook prosumers are discussing on sports especially cricket more in the cyber-world and trying to build identity, forming public discourse. For instance, the meme figure-5 shows the Bangladesh-Sri Lanka Cricket series and their expression regarding the recent match.

Therefore, the sample page has been taken for analysis that used memes to disseminate several types of representations created for different motives. Internet memes mainly focus on everyday lives of Bangladeshi people. But more importantly, alongside entertainment, the page regularly posted satires centering important national, political or social issues, for instance, criticisms of government responses in crisis situations, mockery of media for their inactions and negligence in situations where media interventions were mandatory, caricatures of questionable social conventions and practices, use of patriotic empathy to sow seeds of nationalism and many more. 


\section{Conclusion}

Based on the analysis this study can be assumed that Internet memes in general are not just forms of entertainment, but rather used as a means of communication. The findings also noted that photo based internet memes primarily revealed a new approach to interactions and public participation among prosumers. Images and texts used in the memes studied represent the popular Bangladeshi culture. In most cases, comical arguments are established through such compositions that only Bangladeshi prosumers would be able to deconstruct for deciphering meanings. In addition, these memes are interpreted by the prosumers, who deduce certain connotations from each meme. Internet memes are also interpreted in conjunction with the environment in which they are experienced by the prosumers. So, Internet meme is a kind of vernacular creativity that reflects cultural practices through visual images. By creating and remixing protagonists and texts, meme users convey their emotions, standpoints and opinions on national, political, social and their current reality. Units of culture therefore are spread from person to person. The Internet and participant activities assist the Internet meme as it travels among cultures and shapes. As the popularity and usage of Facebook increases, so does the spread of memes from users' or institutions' Facebook profiles that create and share memes among the rest of the users. In case of Bangladesh, Facebook brings the public sphere where conscious citizens engage in the critical debates on contemporary issues. Besides, the culture of mass consumption of entertainment in the age of internet are enabling the development of virtual public sphere, where people come mostly to seek entertainment and end up sharing and talking about social-political issues in that case memes are playing a great role as cultural discourse. Hence, memes as artifacts of participatory digital culture illustrate the duality of structure and examine memes as a form of rhetoric which expand understandings about the ways memes 
function in a participatory media culture. Therefore, it can be said that the world of Internet Memes is vast; the amount of cultural objects created on daily basis is astounding, turning readers into authors and critics and back to readers at a rapid pace.

\section{References}

allin1social.com .2016. Facebook statistics for Bangladesh. Retrieved 31 July, 2016 from http://www.allin1 social.com/facebook-statistics/countries/bangladesh. 
Blair, J. A. 2004. The rhetoric of visual arguments. Inc. A. Hill \& M. Helmers (Eds.) Defining visual rhetorics (pp. 41- 61). Mahwah, N.J.: Lawrence Erlbaum Associates.

Burgess, J.2008. 'All your chocolate rain are belong to us?' Viral video, YouTube and the dynamics of participatory culture. In G. Lovink \& S. Niederer (Eds.) Video vortex reader: Responses to YouTube (pp.101-109). Amsterdam: Institute of Network Cultures.

Brown, N. 2014. A defense of form: Internet memes and Confucian ritual. Stance (1943-1880), 719-27.

Blackmore, S.J. 1999. Memes, minds, and consciousness. In The Future of Psychology. Stichting VSPA Ledenservice, Amsterdam, 39-41.

Chen, Carl, 2012. The Creation and Meaning of Internet Memes in 4chan: Popular Internet Culture in the Age of Online Digital Reproduction. Retrieved from http://citeseerx.ist.psu.edu/viewdoc/download;jsessionid=38C153206A4879CBCC96AF7B5FC8 C7A0?doi=10.1.1.363.7029\&rep=rep1\&type $=$ pdf

Dawkins, R.1978. The Selfish Gene. New York: Oxford University Press.

Dawkins, Richard, 1989. The Selfish Gene (2 ed.), Oxford University Press, p. 192, ISBN 0-19286092-5.

Ding , Zhao, 2015. INVESTIGATING ASIAN/ASIAN AMERICANS’ IDENTITY NEGOTIATION (Unpublished master's Thesis). Master of Arts (MA), Bowling Green State University, Media and Communication.

https://etd.ohiolink.edu/pg_10?0::NO:10:P10_ETD_SUBID:102689

Facebook Information. Retrieved July 31, 2016, from

http://www.internetworldstats.com/asia.htm\#bd. 
Facebook, Investor Relation. (2016). Retrieved 31 July, 2016 from

http://investor.fb.com/releasedetail.cfm? ReleaseID=908022.

Foss, S. K. (2004). Framing the study of visual rhetoric: Toward a transformation of rhetorical theory. In C. A. Hill \& M. Helmers (Eds.) Defining visual rhetorics (pp. 303-313).Mahwah, N.J.: Lawrence Erlbaum Associates.

Foss, S. K. (2005). Theory of visual rhetoric. In: K. Smith, Moriarty, S. E. and K> Kenney,ed., Handbook of Visual Communication: Theory, Methods and Media, $1^{\text {st }}$ ed.[online] Mahwah, New Jersey: Lawrence Erlbaum. www.sonjafoss.com/html/Foss41.pdf

Foss, S. K. (2008). Rhetorical criticism: Exploration and practice (4th ed.). Prospect Heights, Ill: Waveland Press.

Floor, N. 2000. Web Business Engineering. Retrieved January 29, 2012, Retrieved from http://www.informit.com/articles/article.aspx?p=19996 https://www.socialbakers.com/statistics/facebook/pages/detail/1439584546253425-earki http://www.allin1 social.com/facebook-statistics/countries/bangladesh.

http://www.alexa.com/siteinfo/earki.com

http://www.earki.com/

https://www.facebook.com/earkidotcom/

Huntington, H. E. 2013. Subversive memes: Internet memes as a form of visual rhetoric.Selected Papers of Internet Research 14.0. Retrieved from http://www.academia.edu/5415739/Subversive_Memes_Internet_Memes_as_a_Form_of_Visual _Rhetoric

Hristova, S. 2013. Occupy Wall Street Meets Occupy Iraq On Remembering and Forgetting in a Digital Age. Radical History Review, (117), 83-97. doi:10.1215/01636545-2210473 
Internet World Stats. 2016. Asia Marketing Research, Internet Usage, Population Statistics and Facebook Information. Retrieved July 31, 2016, from http://www.internetworldstats.com/asia.htm\#bd.

Jenkins, H. 2009. Confronting the challenges of participatory culture: Media education for the21st Century. The John D. and Catherine T. MacArthur Foundation Reports on Digital Media and Learning. Cambridge: The MIT Press.

Jenkins, H. 2002. Cyberspace and race. Technology Review, April. Available at: http://www.technologyreview.com/web/12797/.

Jenkins, E. S. 2014. The modes of visual rhetoric: Circulating memes as expressions. QuarterlyJournal of Speech, 100(4), 442-466. doi: 10.1080/00335630.2014.989258

Kaplan, A. M., \& Haenlein, M.2010. Users of the world, unite! The challenges and opportunities of Social Media. Business Horizons, Vol. 53, pp. 61.

Knobel, M., \& Lankshear, C. 2007. Online memes, affinities, and cultural production. In M.Knobel \& C. Lankshear (Eds.), A new literacies sampler (pp. 199-227). New York, N.Y.:Peter Lang.

Levinson, Noah, David, 2012. LOLs, Lulz, and ROFL: The Culture, Fun, and Serious Business of Internet Memes BPhil. University of Pittsburgh, 2012 .http://d scholarship.pitt.edu/13531/1/LevinsonND_etdPitt2012_Revised072313-1.pdf Marshall, G. 1995. The Internet and memetics. Unpublished paper presented at Einstein meets Magritte:An interdisciplinary reflection on science, nature, human action and society, May $29-$ June 3, Brussels, Belgium. 
Milner, R. M. 2012. The world made meme: Discourse and identity in participatory media (Unpublished doctoral dissertation). University of Kansas, Lawrence, KS. Retrieved from academia.edu

Milner, R. M. 2013. FCJ-156 Hacking the social: Internet meme, identity antagonism, and the logic of lulz. The Fibreculture Journal. Retrieved from http://twentytwo.fibreculturejournal.org/fcj-156-hacking-the-social-internet-memesidentityantagonism-and-the-logic-of-lulz/

Miltner, K. 2011. Srsly phenomenal: An investigation into the appeal of LOLcats. (Unpublished master's dissertation). London School of Economics, London, UK. Retrieved from http://katemiltner.com/

McLuhan, M.1964. Understanding Media: The Extension of Man. New York: McGraw Hill. Wiggins, B. \& Bowers, B. 2014. Memes as genre: A structurational analysis of the memescape. New media and society, 1-21.

Mina, A. X. 2012. Hong Kong citizens' online, memetic protest. 88 Bar [blog].

Retrieved from http://www.88-bar.com/2012/09/hong-kong-citizens-online-memeticprotest

Nakamura, L. 2002. Cybertypes: Race, ethnicity, and identity on the Internet. New York:

Routledge.

Ohiagu, O. P. \& Okorie, V. O. 2014. Social Media: Shaping and Transmitting Popular Culture. Covenant Journal of Communication (CJOC), Vol. 2, No. 1, pp. 93-108.

Preez, Amanda, du and Lombard, Elanie, 2014. The role of memes in the construction of Facebook personae. Communication · September 2014. DOI: 10.1080/02500167.2014.938671 https://www.researchgate.net/publication/271623834_The_role_of_memes_in_the_construction of_Facebook_personae 
Sulhan, Ibnu, 2016. Internet Meme Analysis: Interpretative Semiotic Analysis On the 'Scumbag Steve'. Journal of Communication Studies | Vol. 3 No.1, Januari - Juni 2016. Retrieved fromjournal.lspr.edu/index.php/vol3no1/article/download/16/28

Sujan, A. 2015. Rate of Facebook users more than birth in Bangladesh. Retrieved July 31, 2016, from risingbd.com: http://www.risingbd.com/english/rate-of-facebook-users-more-than-birth-inbangladesh/25535.

Shifman, L. 2014. Memes in Digital Culture. MA: MIT Press.

Shifman, L. 2013. Memes in a digital world: Reconciling with a conceptual troublemaker.Journal of Computer-Mediated Communication, 18(3), 362-377. doi:10.1111/jcc4.12013

Shifman, L. 2011. An anatomy of a YouTube meme. New Media \& Society, 14(2), 187-203.

Spitzberg, B. H. 2014. Toward a model of meme diffusion (M3D). Communication Theory,24(3), 311-339.

Toffler, Alvin. 1980. The Third Wave. New York: Bantam Books.

Turhan, Abdul, Aziz, 2013. Analysis on Internet Memes using Semiotics.

http://english.binus.ac.id/2013/06/24/analysis-on-internet-memes-using-semiotics/

Vickery, J. R. 2014. The curious case of confession bear: The reappropriation of online macroimagememes. Information, Communication \& Society, 17(3), 301-325.

Wiggins, B. \& Bowers, B. 2014. Memes as genre: A structurational analysis of the memescape. New media and society, 1-21.

Yang, P. 2012. Who Am I in Virtual Space? A Dialectical Approach to Students' Online Identity Expression. In Cheong, P. H., Martin, J. N. \& Macfadyen, L. P. (Eds.), New Media and Intercultural Communication: Identity, Community and Politics (pp. 109-122). New York: Peter Lang Publishing, Inc. 
